\title{
Erratum to: Evaluation of ultra high performance liquid chromatography columns for the analysis of unmodified and antisense oligonucleotides
}

\author{
Sylwia Studzińska $\cdot$ Bogusław Buszewski
}

Received: 10 September 2014 / Accepted: 10 September 2014 /Published online: 26 September 2014

(C) Springer-Verlag Berlin Heidelberg 2014

Erratum to: Anal Bioanal Chem

DOI 10.1007/s00216-014-7959-5

The publisher regrets that the following correction was not implemented in the final proof of this contribution. It should read throughout the entire article "ultra high performance liquid chromatography".

Our sincere apologies to the authors.

The online version of the original article can be found at http:// dx.doi.org/10.1007/s00216-014-7959-5.

S. Studzińska $(\bowtie) \cdot$ B. Buszewski

Faculty of Chemistry, Nicolaus Copernicus University, 7 Gagarin

Str., 87-100 Toruń, Poland

e-mail: kowalska@chem.umk.pl 